\title{
Conflitos e possibilidades para um desenvolvimento do turismo de base comunitária na Vila de Barra do Una em Peruíbe (SP)
}

Conflicts and possibilities for development of community-based tourism in Vila da Barra do Una in Peruibe (SP)

Los conflictos y las posibilidades de desarrollo del turismo de base comunitaria en el pueblo Vila de Barra do Una en Peruibe (SP)

http://dx.doi.org/10.18472/cvt.16n2.2016.1167

Paulo Tácio Aires Ferreira 〈paulotacio@usp.br >

Universidade de São Paulo, USP, Brasil.

Sidnei Raimundo 〈sraimundo@usp.br >

Universidade de São Paulo, USP, Brasil.

CRONOLOGIA DO PROCESSO EDITORIAL

Recebimento do artigo: 12-nov-2015

Aceite: $17-j u l-2016$

FORMATO PARA CITAÇÃO DESTE ARTIGO

FERREIRA, P. T. A; RAIMUNDO, S. Conflitos e possibilidades para um desenvolvimento do turismo de base comunitária na Vila de Barra do Una em Peruíbe (SP). Caderno Virtual de Turismo. Rio de Janeiro, v. 16, n. 2, p. 150-167, ago. 2016.

$$
\text { REALIZAÇÃO }
$$



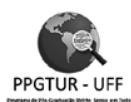

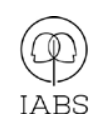

APOIO INSTITUCIONAL

COPPE
EDIÇÃO

PATROCÍNIO

IR⿴囗十口:
Q9 


\section{RESUMO}

As Unidades de Conservação foram criadas de uma maneira antidemocrática, incorporando em suas áreas o território de comunidades tradicionais. O cerceamento de atividades tradicionais, como agricultura e extrativismo, levou tais comunidades a desenvolver atividades e serviços voltados ao turismo. O objetivo deste artigo foi avaliar as possibilidades de desenvolvimento e gestão de um turismo de base comunitária na Vila de Barra do Una, inserida na Reserva de Desenvolvimento Sustentável Barra do Una (RDSBU), analisando os conflitos e impactos socioculturais ocasionados pelas atividades de turismo. O método utilizado foi o etnográfico, baseado em uma descrição densa, na observação participante e em entrevistas com atores-chaves: líderes da comunidade, gestores da unidade de conservação e veranistas. Os resultados apresentam pontos positivos e negativos na comunidade para o desenvolvimento do turismo de base comunitária ante sua organização interna e na relação com os atores externos, notadamente a gestão da unidade de conservação.

Palavras-chave: Turismo de base Comunitária. Unidades de Conservação. Reserva de Desenvolvimento Sustentável. Vila Barra do Una - Peruíbe.

\section{ABSTRACT}

The protected areas were created in an undemocratic way, incorporating in their areas the territory of traditional communities. The restriction traditional activities such as agriculture and extraction, took such communities to develop activities and services geared to tourism. The aim of this paper was to evaluate the possibilities for development and management of a community-based tourism in Barra do Una village, part of the Sustainable Development Reserve Una Barra (RDSBU), analyzing conflicts and socio-cultural impacts caused by tourism activities. The method used was ethnographic, based on a dense description, the participant observation and interviews with key ers: community leaders, managers of conservation and vacationers. The results are positive and negative points in the community for the development of community-based tourism across its internal organization and the relationship with external actors, notably the management of the protected area.

Keywords: Community-based Tourism. Protected Areas. Sustainable Development Reserve. Vila Barra do Una - Peruíbe.

\section{RESUMEN}

Las áreas protegidas fueron creadas de manera antidemocrática, incorporando en sus áreas los territorios de comunidades tradicionales. La restricción de actividades tradicionales como la agricultura y la extracción, tomaron dichas comunidades para desarrollar actividades y servicios orientados al turismo. El objetivo de este trabajo fue evaluar las posibilidades de desarrollo y gestión de un turismo basado en la comunidad en Barra do aldea Una, parte del desarrollo de la Reserva Una barra Sostenible (RDSBU), el análisis de los conflictos e impactos socio-culturales causados por las actividades turísticas. El método utilizado fue etnográfico, basado en una descripción densa, la observación participante y las entrevistas con los principales interesados: los líderes comunitarios, gestores de unidad de conservación y vacacionistas. Los resultados son los puntos positivos y negativos en la comunidad para el desarrollo del turismo basado en la comunidad a través de su organización interna y la relación con los actores externos, en particular el manejo del área protegida.

Palavras clave: Turismo basado en la comunidad. Areas protegidas. Reserva de Desarrollo Sostenible. Vila Barra do Una - Peruíbe 


\section{INTRODUÇÃO}

O tema apresentado neste artigo está relacionado ao desenvolvimento do turismo ligado à inclusão social e à participação política para fomento de práticas de atividades turísticas na Vila de Barra do Una, localizada no município de Peruíbe, no estado de São Paulo, onde ocorrem intensas lutas e mobilizações sociais, travadas principalmente com o Estado (QUEIROZ, 1992; NUNES, 2003; SANCHES, 2004). A comunidade tradicional caiçara da Vila Barra do Una mantém ainda atividades de subsistência, como a pesca, mas Nunes (2003) já constatava uma mudança, de que o turismo estava tendo forte relevância na economia dos moradores da região, pois o lugar "transformou-se num bairro de veranistas, onde os antigos pescadores são hoje caseiros, donos de pequenos comércios, barqueiros, etc. O número daqueles que exercem somente atividades de pesca e roça é muito diminuto" (NUNES, 2003, p. 75).

Diante disso, observa-se que a comunidade de Barra do Una é composta por um grupo social heterogêneo, não apenas caiçaras, mas, também, outros ocupantes, não tradicionais, como veranistas. Os moradores tradicionais e ocupantes ocasionais não tradicionais, em muitas ocasiões possuem interesses comuns, principalmente no sentido de pretenderem que suas residências e a posse delas sejam mantidas na localidade. Isso porque há ainda a preocupação de eles, principalmente os veranistas, serem retirados. No passado, quando a área era uma Estação Ecológica (Esec) ${ }^{1}$, - a Estação Ecológica Jureia-Itatins (EEJI), que vigorou entre os anos de 1986 a 2013 - não permitia moradores tradicionais caiçaras nem veranistas. Mesmo com mudanças recentes, com a transformação do local em uma Reserva de Desenvolvimento Sustentável (RDS) ${ }^{2}$, vide Figura 2, agora uma área protegida mais flexível, os veranistas não têm direito assegurado de permanência, não satisfazendo, assim, às aspirações de todos na vila. Em uma RDS os principais detentores de direitos são as populações tradicionais, que no caso da Vila de Barra do Una, são os caiçaras.

\footnotetext{
1 Área protegida que tem como objetivo a preservação da natureza e a realização de pesquisas científicas. É de posse e domínio públicos, sendo que as áreas particulares incluídas em seus limites serão desapropriadas, de acordo com o que dispõe a Lei n. 9.985, portanto, com proibição de moradores em seu interior.

2 Área protegida que abriga populações tradicionais, cuja existência baseia-se em sistemas sustentáveis de exploração dos recursos naturais, desenvolvidos ao longo de gerações e adaptados às condições ecológicas locais e que desempenham um papel fundamental na proteção da natureza e na manutenção da diversidade biológica. Lei n. 9.985.
} 


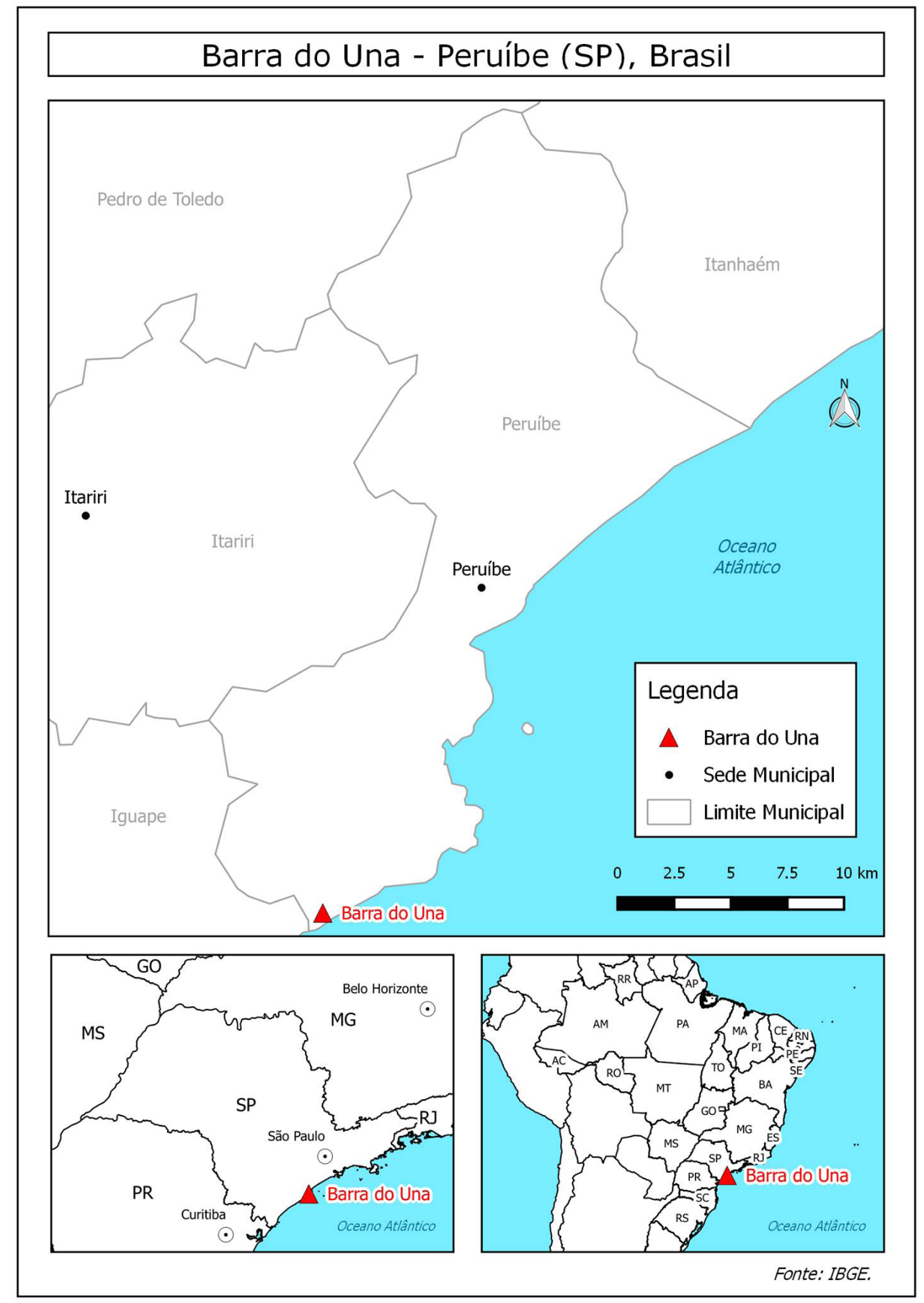

Figura 1 - Área de estudo - localização da Vila de Barra do Una 


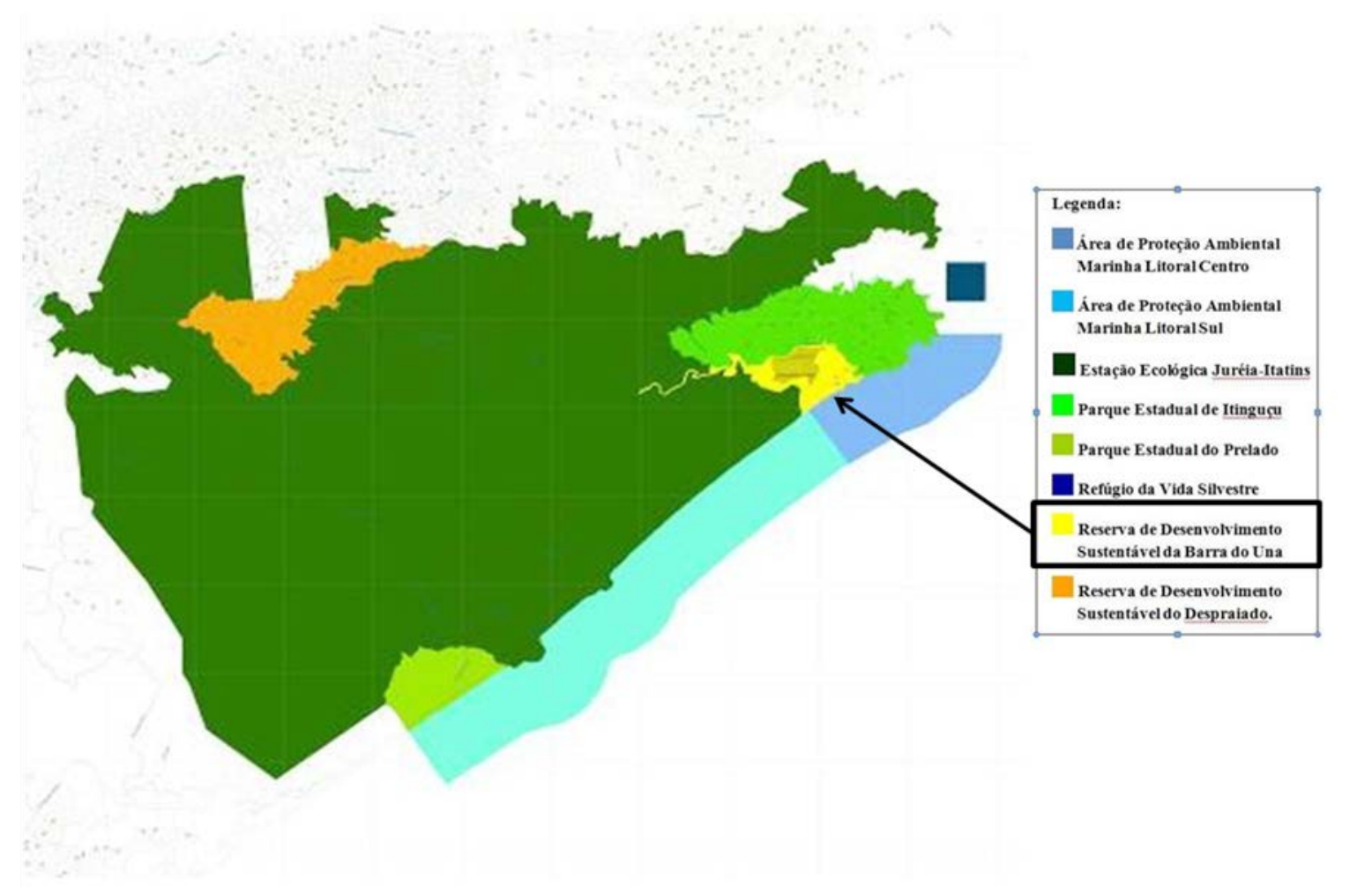

\section{Figura 2 - Croqui do Mosaico e RDS Barra do Una ${ }^{3}$, com destaque para a área de estudo, indicado em amarelo no croqui.}

A Vila de Barra do Una, com as comunidades incluídas na antiga EEJI, passou por um acentuado histórico de lutas políticas, que em alguns momentos, obtiveram algumas vitórias. Em 2006 a EEJI foi transformada no Mosaico de Unidades de Conservação Jureia-Itatins contendo seis categorias, entre tais está a Reserva de Desenvolvimento Sustentável da Barra do Una (RDSBU). Um dos principais motivos da criação desse mosaico foi atender às reivindicações das comunidades locais, procurando resolver, assim, problemas fundiários. Em 2009 uma Ação Direta de Inconstitucionalidade (Adin) suspendeu as atividades do mosaico e retornou a condição dessa Unidade de Conservação à Estação Ecológica com a mesma extensão de área anterior (FUNDAÇÃO FLORESTAL, 2010).

A grande disputa que girou em torno dessas mudanças de unidades está entre a influente ideologia preservacionista de muitos ambientalistas, que considera que as áreas protegidas não devem possuir populações humanas em seu interior, contra movimentos socioambientais da Jureia que se amparam na Convenção 169 sobre Povos Indígenas e Tribais da Organização Internacional do Trabalho (OIT) e o Decreto 6.040 que rege sobre a proteção das comunidades tradicionais (NUNES, 2003; FERREIRA, 2012).

No dia 06 de março de 2013, após várias discussões, a Assembleia Legislativa de São Paulo aprovou alterações nos limites da EEJI tornando-a novamente um Mosaico de Unidades de Conservação. Essa lei foi sancionada pelo governador de São Paulo no dia 08 de abril de 2013. Todavia, em desacordo com a constituição do Mosaico, um procurador-geral da Justiça do Estado de São Paulo expediu no dia 05 de de-

3 Fonte: http://www.al.sp.gov.br/repositorio/legislacao/lei/2013/lei-14982-08.04.2013.html 
zembro de 2013 uma "liminar para suspender a eficácia da lei impugnada". Ou seja, novamente uma Ação Direta de Inconstitucionalidade, de n. 0199748-62.2013.8.26.0000, alegando que a nova Lei do Mosaico era inconstitucional e violava o "princípio da proibição de retrocesso ambiental", e que não é possível a "transformação de uma unidade de conservação de proteção integral" em uma de "uso sustentável", entre outros diversos argumentos. No entanto, essa liminar foi entendida como improcedente no dia 04 de junho de 2014.

A respeito do desenvolvimento do turismo, a própria comunidade já pretendeu instituir o turismo de base comunitária com auxílio de instituições como o governo federal, participando, por exemplo, de editais de fomento ao turismo por ele promovido. Porém, essa tentativa não foi bem-sucedida por conta de embates envolvendo, principalmente, a questão da Vila de Barra do Una estar inserida à época na Estação Ecológica, que não permitia a presença de moradores e tampouco o desenvolvimento de atividades turísticas, do ponto de vista econômico (BARTHOLO; BURSZTYN; SANSOLO, 2009, p. 474).

Baseado nessas informações levantou-se como hipóteses que as atividades turísticas já estabelecidas na Vila Barra do Una têm algumas características de turismo de base comunitária. Há claramente uma aproximação dos nativos com os turistas, seja em pousadas ou campings, ou mesmo no desenvolvimento de atividades como a pesca artesanal ou esportiva, em monitorias, nas recepções a grupos de escolares e de universidade. Aventou-se que esses contatos suplantam a simples prestação de serviço, e tornam-se experiências de sociabilidade muito interessantes, onde a vida comunitária e seus aspectos sociais, econômicos e culturais estão imbricados.

Além de uma evidente experiência com o turismo, existe na vila uma razoável organização socioprodutiva da atividade. Os moradores possuem uma associação, a Sociedade Amigos da Vila de Barra do Una (Sabu) que delibera sobre questões de turismo, organizam festas, mantêm parceiros, dividem atividades de recepção de turistas, embora isso aconteça de maneira incipiente. Existe, portanto, um espaço onde temas, como o turismo, podem ser discutidos de uma forma participativa.

Constatam-se muitas preocupações que dizem respeito às muitas restrições impostas aos moradores que trabalham com o turismo. São corriqueiras ações por parte da instituição gestora da área (Fundação Florestal), proibindo ou dificultando a manutenção de infraestrutura básica ou mesmo turística. Em muitas dessas ações há processos burocráticos que impedem, ou dificultam que moradores executem reformas de seus equipamentos, como quartos de pousadas, pequenas construções, ou reformas em campings.

Todos esses acontecimentos apontam para uma profunda relação conflituosa dos moradores e veranistas contra a Fundação Florestal, que instituiu regras e normas para a área em total desacordo aos estilos de vida e anseios dos moradores da vila. Mesmo em uma RDS, os ocupantes ainda são cerceados pelos órgãos de governo de desenvolver o turismo na região.

Nesse sentido, o objetivo geral deste artigo foi avaliar as possibilidades de desenvolvimento e gestão de um turismo de base comunitária na Vila de Barra do Una, inserida na Reserva de Desenvolvimento Sustentável Barra do Una (RDSBU), analisando os conflitos e impactos socioculturais ocasionados pelas atividades de turismo. 


\section{MÉTODO}

Esta pesquisa ancorou-se nas relações entre turismo e antropologia. A pesquisa foi realizada por meio de entrevistas e pesquisa de campo de tipo etnográfico, aos moldes da descrição densa, abordagem postulada por Geertz (2012). O intuito foi analisar o olhar, do ponto de vista interpretativo da comunidade local (moradores, associações, gestores, instituições governamentais, lideranças) da Vila de Barra do Una diante da atividade de turismo, as possibilidades de implantação de um turismo de base local, bem como buscar as relações dos moradores com os muitos turistas que frequentam a região, com seus distintos propósitos. Disso aflorou uma "teia de significados", como propõe Geertz (2012), de onde se permitiu correlacionar aos objetivos da pesquisa.

Observou-se as experiências vividas pelos informantes, por meio de observação assistemática ${ }^{4}$ com intuito de construir uma profunda descrição dos fatos. Nessa abordagem, como aponta Geertz fazer etnografia:

[...] é estabelecer relações, selecionar informantes, transcrever textos, levantar genealogias, mapear campos, manter um diário, e assim por diante. Mas não são essas coisas, as técnicas e os processos determinados, que definem o empreendimento. O que o define é o tipo de esforço intelectual que ele representa: um risco elaborado para uma "descrição densa". (GEERTZ, 2012, p. 4)

E para ele, os objetivos da descrição densa e teoria interpretativa da cultura são: "tirar grandes conclusões a partir de fatos pequenos, mas densamente entrelaçados; apoiar amplas afirmativas sobre o papel da cultura na construção da vida coletiva empenhando-as exatamente em especificações complexas" (GEERTZ, 2012, p. 19-20).

O uso da antropologia e etnografia interpretativa no sentido de se avaliar o turismo de base comunitária compõe elementos interessantes para fornecer subsídios com vistas a um entendimento mais integral da área de estudo, a saber, seus conflitos sociais, políticos e territoriais.

Complementarmente, a prática de campo para realização desta pesquisa se deu com a observação participante ${ }^{5}$. As atividades conduzidas por tal técnica ocorreram por meio de visitas ao local de estudo, instalando-se em meios de hospedagens como pousadas e campings, o que possibilitou conversas com proprietários de equipamentos turísticos e turistas; participação em reuniões com gestores, líderes comunitários em assuntos que tratam de discussões sobre o turismo na localidade; participação em demais festas e eventos tradicionais na região; participação em atividades promovidas por órgãos públicos; passeios como caminhadas ecológicas, visitas a atrativos, entre outras ações que trouxeram contato com os informantes. Além disso, procurou-se visitar o local em diversas épocas, em feriados e festividades locais.

As visitas proporcionaram a coleta de dados próxima à realidade local, as situações de seus cotidianos, com a observação do desenvolvimento das atividades de turismo, e também outras relativas a seus coti-

\footnotetext{
4 Para Lakatos, consiste em recolher e registrar os fatos da realidade sem que o pesquisador utilize meios técnicos especiais, ou precise fazer perguntas diretas (LAKATOS, 2010, p. 175).

5 Segundo Minayo (2007): “a técnica da observação participante se realiza através do contato direto do pesquisador com o fenômeno observado para obter informações sobre a realidade dos atores sociais em seu próprio contexto. 0 observador, enquanto parte do contexto de observação, estabelece uma relação face a face com os observados. Nesse processo, ele, ao mesmo tempo, pode modificar e ser modificado pelo contexto. A importância dessa técnica reside no fato de podermos captar uma variedade de situações ou fenômenos que não são obtidos por meio de perguntas, uma vez que observados diretamente na própria realidade, transmitem o que há de mais ponderável e evasivo na vida real." (MINAYO, 2007, p. 59-60)
} 
dianos. Era nas situações de informalidade que as falas sobre conflitos apareciam com mais frequência, muito mais que nas entrevistas, pois se sentiam à vontade para se posicionarem sem se preocupar em ser censurados.

Foram realizadas nove entrevistas "não estruturadas", como forma de explorar melhor um assunto, no caso os conflitos que derivam da atividade turística, por meio de perguntas abertas em conversa informal (LAKATOS, 2009, p. 180). Utilizaram-se roteiros de entrevista diversificados que se baseiam em histórico da localidade, adequando-se às características, principalmente de faixa etária, do entrevistado. As entrevistas complementaram a observação participante, colhendo dados específicos sobre algumas experiências que, embora sejam particulares, refletem um sentimento coletivo dos moradores do bairro. Em todas as entrevistas foram solicitadas autorizações aos moradores para o uso de suas falas.

Os registros foram feitos com diversos materiais: cadernos de campo, máquina fotográfica e gravador digital. Foram instrumentos que ajudaram a registrar muitos fatos, ou como Laplantine (2004) se refere, a "escrever contra o esquecimento", e também Geertz (2012, p. 15) que menciona três características da etnografia

[...] ela é interpretativa; o que ela interpreta é o fluxo do discurso social e a interpretação envolvida consiste em tentar salvar o "dito" num tal discurso da sua possibilidade de extinguir-se e fixá-lo em formas pesquisáveis.

Por fim, ainda compondo a base de análise etnográfica, também foi utilizada uma gama de documentos diversificados. Alguns merecem destaque: estudos técnicos da Fundação Florestal, pré-Plano de manejo elaborado pela União dos Moradores da Jureia (UMJ); fascículo elaborado pela mesma UMJ em parceria com a Universidade Estadual de Campinas (Unicamp); projetos da Associação de Moradores e Ocupantes da Vila de Barra do Una (AMO); atas de reuniões da formação do primeiro conselho da RDS (2006-2009).

Importante entender que o recorte tentou basear-se nos discursos e na narrativa dos moradores da vila no tocante às suas percepções sobre o turismo. Com os assuntos demandados, houve um esforço para tratá-los, das particularidades às totalidades.

\section{RESULTADOS}

\section{A comunidade: tradicionais e ocupantes não tradicionais}

Em geral, os povos chamados de caiçaras ocupam as regiões litorâneas do Brasil, especificamente, do estado do Rio de Janeiro até o Paraná "onde se desenvolveu um modo de vida baseado na pequena produção de mercadorias, que associa à agricultura e à pesca, além de elementos culturais comuns, como o linguajar característico, festas e uma forma de ver o mundo" (DIEGUES, 2004, p. 276). Para esse autor, essas regiões, devido às baixas densidades demográficas e de alteração da paisagem, transformaram-se, assim, em áreas protegidas. Com a criação dessas Unidades de Conservação, os caiçaras foram submetidos a uma série de impeditivos para a realização de suas práticas tradicionais.

A formação das comunidades caiçaras se deu por conta da influência dos ciclos econômicos fazendo surgir pequenas vilas em regiões como Paraty, Iguape e Cananeia. Não fugindo à regra da composição do povo brasileiro, os povos caiçaras são fruto de intensa miscigenação entre europeu, índio e negro, ao longo desses cinco séculos de história (SANCHES, 2004). 
O povo caiçara possui um imenso patrimônio cultural, de ordem material, como suas construções, um exemplo é a canoa caiçara e a casa de pau a pique. Mas há também o patrimônio imaterial que se caracteriza por conter diversas manifestações artísticas as quais incluem festas, gastronomia e produções de artesanato. Em eventos que ocorrem anualmente em muitas cidades brasileiras, como as festas da tainha e festa caiçara, acontecem tradicionalmente um famoso baile de fandango que se tornou um importante registro cultural nos territórios caiçaras.

Em 1986 foi criada a Estação Ecológica Jureia-Itatins que gerou fortes conflitos na região. Comunidades vizinhas à Barra do Una, mas não da linha de costa, como Cachoeira do Guilherme que fica distante aproximadamente $15 \mathrm{~km}$ da Vila Barra do Una, sofreram fortes impactos a partir de então. Nessa comunidade, segundo moradores, havia atividades festivas e religiosas como o fandango, o reisado e folia de reis. Também eram celebradas, segundo tradição local, as cerimônias do Dia de Anunciação de Nossa Senhora (25 de março) e Dia de São Miguel (29 de setembro), eventualmente na Cachoeira do Guilherme (MELO, 2004, p. 325).

Na área de estudo, até os anos 1990 e embora estivessem em uma Estação Ecológica, ocorreu o estabelecimento de pessoas e novas famílias na vila com a aquisição de terrenos, casas ou posses. Essas pessoas possuíam origens diversas, algumas com práticas sociais e culturais rurais, outras vindas de grandes cidades, como São Paulo; mas todas contribuiriam para transformar a tessitura social.

Vianna (2008) agrupou os ocupantes em áreas protegidas conforme a situação fundiária, cultural, econômica e localização geográfica. Além dos caiçaras e veranistas, as unidades de conservação podem abrigar também: caipiras, índios, fazendeiros, pecuaristas, pequenos sitiantes, madeireiros, mineradores, grileiros, empresários, assalariados, caseiros, trabalhadores de serviço terciário, funcionários públicos, pesquisadores, turistas, estudantes, posseiros e proprietários (VIANNA, 2008, p. 190).

Para Vianna, o termo veranista refere-se ao "indivíduo que possui uma segunda residência, distante de sua residência fixa, a qual visita temporariamente" (VIANNA, 2008, p. 191) e Tulik (2001) acrescenta "que são propriedades particulares utilizadas temporariamente, nos períodos de tempo livre, por pessoas que têm sua residência permanente em outro lugar" (TULIK, 2002, p. IX).

Atualmente os moradores tradicionais caiçaras realizam múltiplas atividades. Muitas práticas tradicionais como a caça e o roçado foram abandonadas amiúde. Na Vila ainda existem acentuadas características das comunidades tradicionais, como a pesca e coleta de marisco, mesmo que sejam voltadas ao veraneio. Com a chegada de uma quantidade considerável de pessoas de outras regiões, seria certo que a vila iria adotar ares bem particulares. Além dos caiçaras, há também a categoria "adventício", uma denominação criada no Cadastro Geral de Ocupantes no ano de 1990, realizado pela Secretaria de Meio Ambiente do Estado de São Paulo. Essa categoria diz respeito aos moradores e ocupantes não tradicionais vindos de diversas regiões do País, principalmente Minas Gerais e Nordeste. Dividem-se em adventício antigo, que chegaram antes da EEJI; e recentes, que chegaram após a instalação da EEJI.

Alguns ocupantes residem, mas não são tradicionais; outros ocupantes não residem, mas são tradicionais (pois embora tenham nascido na vila, migraram para outros locais, mas mantêm laços, visitando a área esporadicamente, ou mantendo alguma infraestrutura, como ranchos de pesca). Finalmente, há os que não residem e nem são tradicionais. A atribuição de "veranista", "proprietários de segunda residência" cabe mais a estes últimos, embora essa denominação não seja de seus agrados. 
A aproximação "afetiva" dos proprietários de segunda residência com as localidades também é um fator importante a se levar em conta e importante a ser apontado nesta pesquisa. Muitos autores concordam que há diferenças claras entre "turistas" e "usuários de segunda residência". Turista, geralmente, não costuma retornar ao local visitado, e nem cria vínculo com a localidade, já:

[...] Os usuários de segundas residências diferem dos turistas propriamente ditos, na medida em que o retorno frequente a uma dada localidade possibilita a criação de um vínculo territorial que se expressa de distintas formas: 1- vínculo afetivo e psicológico com o lugar, sendo esta uma das distinções mais importantes entre o usuário da segunda residência e o turista; 2 - vínculos de vizinhanças e sociabilidade com outros usuários de segundas residências e moradores locais (FONSECA, 2012, p. 13).

Em estudo técnico realizado pela Fundação Florestal em 2009 apontou a existência de 49 famílias de residentes, aproximadamente, 143 indivíduos, e mais 87 famílias de não residentes.

A questão da permanência de ocupantes não tradicionais, ou "os de fora", como foi explicitado por um membro do grupo, é recorrente. A Fundação Florestal, como forma de avaliar a condição dos tradicionais e adventícios antigos, realizou um laudo antropológico no ano de 2010. Esse laudo tem sido fortemente questionado pelos ocupantes. Intrigados com a presença das antropólogas na vila, a AMO enviou uma notificação perguntando o porquê de não serem indagados sobre seu histórico com a vila. Integrantes da AMO contra-argumentam que quem deve se autodeterminar, como exposto no decreto, são as próprias pessoas da vila, ou quem tem ligação com ela, questionam, além do mais, o termo "natividade" no decreto. Uma liderança, que já foi presidente da Sabu, relatou contrariado e contrariando o fato de ter sido caracterizado como "tradicional". Ele é casado com uma moradora tradicional, incluída no Laudo. Desse modo ele é diretamente apontado como tradicional, mas, descarta ser morador tradicional, e contesta também o laudo: "me classificaram como tradicional, mas não sou".

O turismo para muitas comunidades onde residem caiçaras, do litoral sul do Rio de Janeiro até o Paraná, tem se tornado a principal fonte de renda. Esses grupos praticamente foram impelidos a essa atividade econômica. Também é importante notar que parte dos territórios que restaram tem sofrido a carência de serviços básicos, como educação, saúde, transporte, saneamento, comunicações, fato este que obsta às comunidades caiçaras o desenvolvimento de autonomia para gestão de seus meios de produção.

\section{DISCUSSÃO: O TURISMO NA VILA DE BARRA DO UNA}

No decorrer do ano, fora da temporada de veraneio, as práticas de turismo estão ligadas à pesca, coleta de mariscos, cabendo principalmente aos homens, embora também haja mulheres que ajudem nesses tipos de trabalho. Estas se dedicam aos afazeres ligados aos meios de hospedagem, restaurantes e demais serviços domiciliares. Nesse período, diversos moradores realizam trabalhos: atuando como caseiros, executando pequenas reformas, ou trabalhando na limpeza das casas de proprietários de segunda residência.

Nesse período recebem pouquíssimos turistas, frequentemente grupos escolares que se revezam pelos campings. Essa é uma forma que os moradores encontraram para manter a renda e distribuí-la de maneira mais coletiva. Todavia, tal divisão está em debate, e há polêmicas que divide opiniões e algumas críticas quanto ao real funcionamento. Alguns moradores e proprietários de campings dizem não serem contemplados por esse rodízio, afirmando que em parte fica muito centralizado na mão das mesmas famílias ou estabelecimentos. Ainda é uma incipiente experiência, entretanto, é uma importante ação coletiva, apesar de suas supostas contradições. 
$\mathrm{Na}$ época em que se aproxima a temporada de verão, os trabalhos se intensificam, mesmo as atividades que não sejam diretamente ligadas ao turismo. Percebi claramente isso em meados de novembro, quando me instalei por semanas na vila.

Como já mencionado, como forma de defenderem seus direitos coletivamente, além da Sabu, que é uma associação liderada pelos moradores que detêm estatuto de tradicionais, e discute sobre assuntos políticos e econômicos, como a pesca e o turismo, há também a Associação de Moradores e Ocupantes de Vila de Barra do Una (AMO), que atua politicamente na defesa dos direitos dos "não tradicionais". Além dessas, outras associações da Jureia como a União dos Moradores da Jureia e mesmo ONGs da região se fazem presentes e já tiveram muitos momentos de parceria com a vila.

O cooperativismo também é presente na vila. Está em andamento um processo de abertura de uma nova cooperativa pelos moradores, que envolve os pescadores e proprietários de restaurantes. Isso é fruto de uma situação controversa: os pescadores costumam vender seus peixes para Peruíbe, ou quando vendem no local, são apenas para os veranistas. Raramente vendem para os proprietários de lanchonetes e restaurantes do bairro, gerando algum conflito interno, ou, pelo menos, uma desunião na comunidade. No entanto, esse dilema está em vias de ser sanado com um acordo entre essas partes, pois os restaurantes terão seus freezers de forma organizada, e serão alocados em um espaço no centro comunitário.

\section{Turismo é fato}

A Vila de Barra do Una, assim como a Jureia, vivenciaram diversos ciclos econômicos (SANCHES, 2004). Nota-se em muitos diálogos com moradores o quão é perceptível que o turismo é um fato já de longa data. Segundo uma moradora, o local era frequentado por muitas pessoas, até mesmo estrangeiros, mas aos poucos isso teve uma diminuição por conta da infraestrutura precária, e também a Estação Ecológica, que possivelmente freou a vinda de turistas, tornando a vila, segundo palavras da própria moradora, "esquecida".

Cumpre retomar Nunes (2003) que não apenas constatou a crescente do turismo na vila, mas também notou mudanças socioestruturais. A vila, à época, já estava amalgamada por moradores que naquele período alternavam suas atividades econômicas. Ramires e Mirella (2003), que estudaram a pesca na região, corroboram a análise dessa transição:

[...] a principal fonte de renda das famílias é proveniente do turismo. Os moradores também trabalham como caseiros na casa dos turistas, comerciantes nos bares, donos de campings, pilotos de barcos para passeios, guias para pesca esportiva e também vendem iscas vivas para os pescadores esportivos (RAMIRES; MIRELLA, 2003).

Em um estudo técnico feito pela Fundação Florestal, até mesmo a instituição se tributou também a referendar as mudanças na atividade produtiva. Desse modo, reitera e reconhece:

Quase todas as famílias entrevistadas na Barra do Una têm entre suas fontes de renda os ganhos do turismo e da pesca, complementadas por outras atividades. A partir dos ganhos por tipo de atividade e período do ano, estimamos a média de ganho por família. No entanto, apenas a renda mensal ligada ao turismo é possível ser estimada, pois os ganhos vêm tanto da baixa como da alta temporada do turismo. Para as demais fontes de renda como a pesca e o extrativismo, os ganhos são somente em período de temporada; para outras fontes, apenas os quem têm serviços fixos, como caseiro, bolsas auxílio e aposentadoria, são mensais. Sendo assim, a renda familiar é constituída por no mínimo duas fontes de renda diferentes e varia ao longo ano. (GRIFO NOSSO) (FUNDAÇÃO FLORESTAL, 2009, p. 85) 
Neste estudo fica claro que a instituição entende que houve e continua ocorrendo processos de mudança, uma vez que o turismo não é uma atividade tradicional, ainda que ele se vincule à vila e às demais atividades tradicionais.

O ex-gestor da EEJI aponta que além do turismo sempre ter existido, há o desdobramento de três segmentos importantes:

Primeiro que o turismo sempre aconteceu ali. Antes da Estação, durante a Estação, sempre aconteceu. Na Barra,
comprovadamente, você tem três atividades, digamos. Uma delas é a pesca, que hoje é um grupo menor que depen-
de forte pra geração de renda, mas ainda tem; o turismo, que é a grande fonte de renda da comunidade; e a relação
veranista-tradicional, que também gera recursos pra eles, na medida em que eles cuidam das coisas... Então, têm
estas três atividades. Elas, dentro do que tá previsto na lei, dão condição pra você fazer os acordos... Até que se re-
solva a questão fundiária.

Igualmente, nessa informação, em que pese a visão de legalidade do gestor que contrasta em alguns casos nos discursos dos moradores e ocupantes não tradicionais, percebe-se sua abertura ao diálogo, e que foi confirmada por diversos moradores e ocupantes não tradicionais, participantes assíduos de reuniões ou discussões sobre a vila.

Mas há moradores que salientaram a importância da pesca, alguns contrapontos que a sazonalidade do turismo lhes impinge, principalmente no inverno. Desse modo, diz uma moradora, que: “... vive do turismo praticamente três meses, que são a temporada. No inverno, a gente passa até dificuldade. Nessa época a gente vive da pesca...”

É perceptível que além das atividades nos equipamentos de infraestrutura turística (bares, restaurantes, pousadas e campings), outros trabalhos são realizados nas casas de muitos veranistas e também de moradores tradicionais, que recrutam ajudantes para executar diversas tarefas de limpeza, ajustes e concertos de equipamentos em residências, entre outros. Geralmente, esses trabalhos ocorrem com mais frequência quando se aproxima a temporada de verão.

O perfil do turista que frequenta a vila é evidentemente ligado à busca de sol e praia. Uma pesquisa realizada pela equipe técnica da Fundação Florestal, no ano de 2012, aponta que os motivos principais dos turistas que procuram a região se dão pelo lazer, ligados a banho de mar e rio. A maioria desses turistas é oriunda da capital paulista, os quais, em parte, possuem segunda residência nas praias próximas a Barra do Una (CORDEIRO et al., 2012).

A vila possui como principal atrativo a Praia da Barra do Una. Outras praias são acessadas por meio de trilhas, como as Praias do Caramborê, onde há camping e moradores, e também a Desertinha que, como fica claro em seu nome, é um local onde não há meios de hospedagem, tampouco moradores, e não é permitido acampar. Todas fazem parte da vila e RDS. A travessia é feita por meio de um costão rochoso, outro atrativo natural, onde há mirantes para as praias do Una e Caramborê.

O fluxo anual turístico, assim como em boa parte do litoral paulista, é bastante sazonal. Na perspectiva dos moradores é afirmado que a temporada de veraneio começa especificamente após o feriado de Natal, dia 26 de dezembro, seguindo até o feriado de carnaval. Outros dizem que a temporada se estende até o feriado da Páscoa. Mas é no final de ano que se vê campings e praia bastante cheios, sendo o feriado de réveillon o que registra os maiores números de visitação. Circular pela vila durante esse período é fácil de ver os meios de hospedagem completamente lotados. 
A pesca é também muito procurada pelos turistas, entre elas a artesanal e a esportiva. Notam-se opiniões distintas entre estes pescadores: os mais antigos trabalham a pesca artesanal; outros mais jovens praticam a pesca esportiva - principalmente os que se localizam em uma região da vila que se chama Tocaia -, na qual se fisga o peixe, mas em seguida o solta. É no Rio Una que a pesca é feita regularmente, onde se encontram também os manguezais e restingas, e a ilha fluvial do Ameixal, possível de visitar por meio de passeios de barcos. Os pescadores também, de certa forma, se tornaram guias (informais), contam a história do local, demonstram também conhecimento dos aspectos biogeográficos. Assim, o turismo associado à pesca artesanal é uma atividade que remonta há mais de vinte anos.

Outras atividades em franca ascensão na região que se utilizam do turismo são a educação ambiental e estudo do meio ambiente. Diversas escolas de ensino fundamental e médio procuram a localidade, além de muitas universidades paulistas. Os moradores, em parcerias com a Fundação Florestal, e também com universidades, já realizaram alguns encontros. Mostram-se organizados para receber grupos, com atendimentos nos meios de hospedagem, restaurantes e também com os monitores da vila, que são em parte os jovens e, além disso, contando com a experiência dos antigos pescadores.

A vila tem forte potencial para desenvolver variados tipos de turismo, como o ecoturismo tanto nas praias, ou no rio, trilhas, entre outros lugares. Há diversas trilhas e caminhos, recentemente algumas destas foram mapeadas. O caiaquismo é um esporte procurado e praticado tanto por moradores como por turistas no rio, que é bem tranquilo de se navegar, como conta um jovem morador, já que o rio é "morto", ou seja, "parado", pois trata-se de um típico rio de planície, sem energia. Muitos desses turistas trazem seus equipamentos. Alguns moradores que habitam casas ao lado do rio também alugam caiaques para turistas.

A organização do turismo tende a ocorrer por meio da Sabu, tendo em vista que todos os seus integrantes trabalham de certa forma com turismo (e também a pesca). Como a associação é dividida em diretorias, algumas delas se dedicam às atividades de turismo. Observando algumas atas da experiência da primeira RDS (2007-2009), o turismo estava presente em quase todas as reuniões. Naquela ocasião organizavam-se em comissões que tratavam especificamente de turismo, e o assunto foi debatido à exaustão nas reuniões, conjuntamente a outros, como: infraestrutura, sistema de comunicação e sinalização; instalação de trilhas interpretativas, atracadouro; ordenação de áreas de camping, pousadas; atendimentos a turistas e visitantes (turista de um dia, como assim está na ata), instituição de códigos para visitante, cadastramento e normas para monitores ambientais e agências operadoras; pretenderam captar fontes de financiamento, fundos para o turismo; propuseram organizar eventos esportivos (surf, canoagem), e até a elaboração de um calendário de eventos anual, passeios de barco, a instalação de centro de visitantes, e até mesmo resgate cultural do fandango, roça e da casa de farinha.

Alguns desses encaminhamentos gerados nessas reuniões foram concretizados, principalmente no tocante à infraestrutura e reforma de casas e estabelecimentos. A pauta infraestrutura estava sempre relacionada à pauta turismo. Também estabeleceram diversas parcerias com grupos próximos, com outras associações, ONGs, prefeitura, a própria FF, entre outros.

Em alguns eventos como nas festas percebe-se visivelmente a coletividade entre a comunidade. A festa da Tainha é um exemplo de parceria, entre Sabu e AMO, e até outros atores. $\mathrm{O}$ atual presidente fez uma autocrítica contando que havia centralizado demais a última festa em suas mãos. Todavia, o turismo no local é, em sua maioria, organizado individualmente, e pautado pelo imediatismo de se discutir ações apenas às vésperas da temporada. Esse problema tem sido colocado por moradores e, também foi apontado por um ex-gestor, que assume responsabilidades da não continuidade de reuniões durante o ano. 
As reuniões comunitárias, embora tenham sofrido também altos e baixos, continuaram, e o turismo permanece com a mesma expressividade em suas pautas. Nas reuniões no último semestre de 2014, por conta da volta da RDS muitos moradores e inclusive lideranças voltaram a frequentar. No mês de novembro, em 2014, houve eleição para membros para compor o conselho.

O ex-gestor aqui entrevistado pretendeu formatar algumas ações, como elaborar roteiros a atrativos para o local, ou até mapear a gastronomia para que os proprietários de restaurantes pudessem divulgar de maneira mais eficiente seus pratos. Também observava a questão da sazonalidade, almejou trabalhar mais assiduamente no tocante ao uso público da Estação Ecológica que era principalmente a educação ambiental. Foram até realizadas parcerias com moradores, inclusive monitores e pescadores.

São ações que apontam que na vila a experiência do diálogo decorrente da existência do turismo, antes mesmo da EEJI, somado às experiências de participação na luta contra as restrições da UC, gerou um conhecimento adquirido na prática muito interessante para os moradores. Como registrado positivamente pelo ex-gestor da FF, foram realizados alguns intercâmbios que colocaram pessoas da comunidade em confronto com outras realidades.

Notam-se muitas ideias, por parte dos moradores, quando se conversa sobre o turismo. Alguns pretendem implementar escolas de surfe; outros querem equipar seus campings, instalar chalés. Fala-se muito na questão financeira. E nesse ponto, é visível que moradores que não possuem empreendimentos turísticos mostram-se ávidos por inserirem-se nessa atividade. Em feriados prolongados, montam suas barracas e vendem pastéis, cocos, água, cerveja, batidas, bolos, mariscos, ostras, e também alugam equipamentos para que os turistas possam tomar duchas e banhos rápidos nas praias.

Para além de muitas atitudes coletivas, o turismo de base comunitária é constantemente mencionado pelos moradores. Irving (2009) reflete que a atitude para formalizar o turismo de base comunitária deve partir de dentro da comunidade e entende que o "turismo de base comunitária resulta de uma demanda direta dos grupos sociais que residem no lugar turístico, e que mantêm com este território uma relação cotidiana de dependência e sobrevivência material e simbólica" (IRVING, 2009, p. 112,). Para Coriolano (2009, p. 66), a propriedade da terra é um elemento importante, pois o turismo comunitário é "Aquele em que as comunidades de forma associativa organizam arranjos produtivos locais, possuindo o controle efetivo das terras e das atividades econômicas associadas à exploração do turismo".

Em entrevistas e conversas com moradores apareceram opiniões sobre o significado de turismo de base comunitária, como esta:

Que eu no início, quando eu ouvi falar no turismo de base comunitária, me apavorou, me assustou. Eu falei: você é louco, deixar uma pessoa na minha casa. Ficar dentro da minha casa, não, nunca. Não vou querer.

Essa mesma moradora disse que sua cabeça ficou muito fechada. Na verdade ela faz uma crítica aos moradores ressaltando um hermetismo excessivo na comunidade e que se leva a indagar qual a possibilidade do turismo de base comunitária ser viável por lá.

Em outra perspectiva, um dos ocupantes não tradicionais observa que os moradores estão preparados para desenvolver o turismo, pois nota que são organizados. Ficou sabendo de uma recepção coletiva e organizada a um grupo que a comunidade se prestou a fazer. E disso refletiu:

O turismo de base comunitária poderia resolver todos os problemas desta sociedade. Porque, por exemplo, se você organizasse a pesca tanto numa cooperativa, nem todos os pescadores precisam pescar todos os dias. Se você tivesse um barco grande, que pudesse ir pro mar, e fizesse equipes que revezasse, com mais gente para puxar a rede. $\mathrm{O}$ 
pescador não precisa pescar todos os dias, ele pode fazer o revezamento, porque é assim que funciona no resto do mundo. Cooperativa de pesca, não tão longe daqui, Santa Catarina, funciona assim, no Chile funciona assim, outros países andinos funciona assim. Por que que na Barra do Una, no Brasil, não pode?

O convívio é nitidamente harmônico entre morador tradicional e veranista. E, além disso, o contato existente entre os turistas e moradores é interessado nos campings, pousadas, bares, restaurantes, passeios de barcos, barracas. Ainda que se obstem muitos impeditivos a um atendimento turístico, os moradores que trabalham com o turismo estão se organizando para receber bem os turistas. As experiências destes são relatadas pelos moradores. Muitos fazem amizades e retornam. Alguns turistas costumam acampar no local desde meados dos anos 1980, quando do início da EEJI. A relação de prestação de serviço é superada pela amizade. Muitos retornam constantemente à vila, porém, mais na época de temporada. Isso é um dos fatores mais importantes para um funcionamento mais efetivo do turismo de base comunitária.

Uma questão preocupante que transpõe vários fatores é o caso do uso excessivo de bebidas e drogas por parte dos turistas. Na comunidade, esse assunto aparece timidamente nas discussões sobre turismo. Alguns moradores se mostraram preocupados, e alguns entenderam que isso existe e "não se pode negar", mas que o turista fazer uso no próprio camping do morador "é muita falta de respeito". Uma ex-gestora também mencionou que muitos turistas bebem excessivamente e usam drogas nos quintais dos moradores (proprietários de campings), desrespeitando o espaço dos moradores. Decerto é assunto que gera preocupações pelo fato de poder atingir os jovens da própria comunidade, como mencionam os moradores.

Da parte dos turistas, estes geralmente reclamam a respeito da falta de infraestrutura turística, principalmente relacionada aos banheiros nos campings, ou sobre o aspecto rudimentar dos meios de hospedagem. Alguns moradores relatavam aos turistas sobre sua situação de impasse em não poder, geralmente, reformar suas casas, explicando aos turistas os problemas burocráticos, e mesmo os políticos e sociais que têm de enfrentar por estarem dentro de uma Unidade de Conservação.

Percebe-se que atualmente há poucas parcerias, ou quase inexistem parcerias com empresas de turismo de outras regiões. Algumas operadoras de turismo, sediadas em Peruíbe, têm gerado alguns questionamentos por parte de moradores da vila. Alguns afirmam haver pouco contato destas com a comunidade.

Neste momento, com a consolidação da RDS, faz-se necessária a criação do Conselho Deliberativo e, posteriormente, a construção do Plano de Manejo que irá orientar diversas atividades, como o turismo, e até mesmo o destino de todos os atores implicados na unidade de conservação. Neste momento de elaboração deste artigo, essa ação ainda não foi realizada.

\section{CONSIDERAÇÕES FINAIS}

Diante dos fatos mencionados acima percebe-se que, de certo modo, a luta comunitária nunca cessou, e que muitos acontecimentos configuram-se sucessivamente como ganhos e perdas. A luta pela permanência de todos (moradores e veranistas) é assunto e demanda de todos. A instabilidade das políticas na instituição de unidades de conservação, e suas características estritamente "preservacionistas" tem sido o principal impeditivo para se consolidar uma participação mais efetiva dos moradores. Há uma clara evidência de que o Estado tem tido pouca habilidade para resolução de conflitos de grande escala, pois criou ao longo dos anos um ambiente antidemocrático e pouco estimulador da participação social. Incipientes políticas públicas de turismo que favoreçam as comunidades também se mostram como fator negativo. 
Desse histórico, foi gerada uma esperança desconfiada nos moradores, uma vez que insiste em persistir um passado malfadado. Agora esses moradores vivem à espreita de um futuro menos incerto. Mas o processo não está dado por encerrado: ocupantes não tradicionais, enredados na teia de conflitos, seguem com a preocupação de perderem suas residências. Moradores preocupam-se com essa potencial mudança estrutural na vila, que os atingirá financeiramente e, além disso, não devemos nos esquecer do laço afetivo claramente existente entre os grupos.

Em aspectos positivos, diante do exposto, aventam-se alguns aspectos relevantes: expressivo enraizamento dos atores com a área; experiência adquirida com a luta política e com atividade de turismo; unidade coletiva e, também, potenciais parceiros adquiridos ao longo do tempo.

Nesse sentido, é interessante colocar em pauta a discussão sobre turismo de base comunitária. De todo modo, é a comunidade, em decisão coletiva, que apontará o futuro de todos, e deve decisivamente participar desta e de todas as decisões que influenciem seus futuros.

\section{REFERÊNCIAS}

ALIER, J. M. O ecologismo dos pobres. São Paulo: Contexto, 2014.

ALMEIDA, A. W. B.; MARIN, R. E. A. (Coord.). Nova Cartografia Social dos povos e comunidades tradicionais do Brasil: comunidades tradicionais caiçaras da Jureia, Iguape-Peruíbe. Manaus: UEA Edições, 2013.

ALMEIDA, W. B. Parecer Antropológico sobre as Comunidades Tradicionais da Jureia. Fevereiro de 2012. Disponível em: 〈https://mwba.files.wordpress.com/2010/06/almeida-et-al-2012-pareceratropologico-sobre-comunidades-tradicionais-da-jureia.pdf〉. Acesso em: 04 mar. 2015.

ARNSTEIN, S. A Ladder of Citizen Participation. Journal of the American Planning Association, Chicago, v. 35, n. 4, p. 216-224, July. 2002, 1st ed., 1969.

BARTHOLO, R; BURSZTYN, I.; SANSOLO, D. G. (Org.). Turismo de Base comunitária: diversidade de olhares e experiências brasileiras. Rio de Janeiro: Letra e Imagem, 2009.

BRASIL. Lei n. 9.985, de 18 de julho de 2000. Institui o Sistema Nacional de Unidades de Conservação. Disponivel em 〈http://www.planalto.gov.br/ccivil_03/leis/l9985.htm〉. Acesso em: 27 out. 2015.

CORDEIRO, V. et al. Características dos visitantes da Estação Ecológica Jureia-Itatins, São Paulo, Brasil: monitoramento e subsídios para a gestão In: VII CONGRESSO BRASILEIRO DE UNIDADES DE CONSERVAÇÃO - VII CBUC, 2012, Natal - RN. Anais... Natal: Fundação O Boticário de Proteção à Natureza, 2012. (Cd-ROM).

CORIOLANO, L. N. M. T. Arranjos produtivos locais do turismo comunitário: atores e cenários em mudança. Fortaleza: Ed. UECE, 2009.

DIEGUES, A. C. S. A mudança cultural como modelo cultural: o caso da cultura caiçara e a urbanização. In: Enciclopédia Caiçara - Volume I - 0 olhar do pesquisador. São Paulo: Editora Hucitec/Nupaub/ CEC/USP, 2004, p. 31-48. 
FERREIRA, L. E. de C. Que os parques possam ser a nossa casa - a luta pela recategorização da Estação Ecológica da Jureia-Itatins. 2011. 201f. Dissertação (Mestrado em Ecologia Aplicada) - Escola Superior de Agricultura Luiz de Queiroz - Esalq/USP.

FONSECA, M. A. (Org.). Segunda residência, lazer e turismo. Natal, RN: Ed. UFRN, 2012.

FUNDAÇÃO FLORESTAL, 2009. Estudo técnico para recategorização de Unidades de Conservação e criação do mosaico de UCs Jureia-Itatins. Disponível em: 〈www.fflorestal.sp.gov.br/.../Estudo\%20 Tecnico_Mosaico_Jureia.pdf〉. Acesso em: 26 fev. 2014.

GEERTZ, C. A interpretação das culturas. Rio de Janeiro: LTC, 2012.

GRAHAM, J.; AMOS, B.; PLUMPTRE, T. Governance Principles for Protected Areas in the 21st Century. Durban. UICN. 2003.

HERCULANO, S. Lá como cá: conflito, injustiça e racismo ambiental. UFF/ICHF-LACTA. 2006.

IRVING, M. de A. Reinventando a reflexão sobre turismo de base comunitária. Inovar é possível. In: BARTHOLO, R; SANSOLO, D; BURSZTYN, I. (Org.). Turismo de base comunitária: diversidade de olhares e experiências brasileiras. Brasília: Letra e Imagem, 2009. p. 108-121.

LAKATOS, E. M.; MARCONI, M. de A. Fundamentos de Metodologia Científica. São Paulo: Atlas, 2010.

LAPLANTINE, F. A descrição etnográfica. Tradução de João Manuel Ribeiro Coelho e Sergio Coelho. São Paulo: Terceira Margem, 2004.

MELO, T. Espaço comunicação e cultura: breve relato de observações sobre a comunidade da Cachoeira do Guilherme. In: Enciclopédia Caiçara - Volume I - O olhar do pesquisador. São Paulo: Editora Hucitec/Nupaub/CEC/USP, 2004, p. 321-339.

MINAYO, M. C. de S. (Org.). Pesquisa Social. Teoria, método e criatividade. 18. ed. Petrópolis: Vozes, 2007.

NUNES, M. Do passado ao futuro dos moradores tradicionais da Estação Ecológica Jureia-Itatins/SP. 2003. 153f. Dissertação (Mestrado em Geografia Física) - Faculdade de Filosofia, Letras e Ciências Humanas.

QUEIROZ, R. C. Atores e reatores da Jureia: ideias e práticas do ecologismo. 1992. 229p. Dissertação (Mestrado). Departamento de Antropologia. Unicamp, Campinas, 1992.

RAMIRES, M.; BARRELLA, W. Ecologia da Pesca Artesanal em Populações Caiçaras da Estação Ecológica de Jureia-Itatins, São Paulo, Brasil. Interciencia (Caracas), Venezuela, v. 28, n. 4, p. 208-213, 2003.

SÃO PAULO. Decreto n. 24.646, de 20 de janeiro de 1986. Cria a Estação Ecológica de Jureia-Itatins e dá providências correlatas. Disponível em: 〈http://governo-sp.jusbrasil.com.br/legislacao/193585/ decreto-24646-86>. Acesso em: 02 ago. 2012. Lei n. 5.649, de 28 de abril de 1987. Cria a Estação Ecológica de Jureia-Itatins e dá outras providências. Disponível em: 〈http://governo-sp. jusbrasil.com.br/ legislacao/190534/lei-5649-87〉. Acesso em: 02 ago. 2012.

. Lei n. 12.406, de 12 de dezembro de 2006. Altera a Lei n. 5.649 de 28 de abril de 1987, que criou a Estação Ecológica de Jureia-Itatins, exclui, reclassifica e incorpora áreas que especifica, institui o Mosaico de Unidades de Conservação da Jureia-Itatins, regulamenta ocupações e dá outras providências. Disponivel em: 〈http://governo-sp.jusbrasil.com.br/legislacao/131089/lei-12406-06〉. Acesso em: 04 mar. 2015. 
. Lei n. 14.982, de 08 de abril de 2013. Altera os limites da Estação Ecológica de JureiaItatins na forma que especifica, e dá outras providências. Disponível em: 〈http://governo-sp.jusbrasil. com.br/legislacao/1034611/lei-14982-13〉. Acesso em: 02 mar. 2015.

SANCHES, R. A. Caiçaras e a Estação Ecológica de Jureia-Itatins: uma abordagem etnográfica e ecológica para o estudo da relação homem - meio ambiente. São Paulo, Fapesp, 2004.

TULIK, O. Turismo e meios de hospedagem: casas de temporada. São Paulo: Roca, 113 p., 2001.

VIANNA, L. P. De invisíveis a Protagonistas. Populações tradicionais e Unidades de Conservação. São Paulo; AnnaBlume: Fapesp, 2008. 